\title{
ORAÇÕES PARA BOBBY: UM ESTUDO DE CASO SOB O OLHAR DA PSICOLOGIA HISTÓRICO-CULTURAL
}

\author{
Maísa Martins Lopes Araújo Brito (iD), Samuel de Menezes Pereira(iD2 \\ Gilson Gomes Coelho (D)3
}

\section{Resumo}

Este trabalho teve como objetivo interpretar a história real narrada no filme Orações para Bobby, com foco no protagonista Bobby e em sua mãe Mary Griffith, fundamentado na teoria histórico-cultural de Lev Vigotski, mostrando a possibilidade de intervenção a partir da psicoterapia baseada na abordagem. A relação com a teoria possibilitou compreender os comportamentos de ambos os personagens como influenciados diretamente pelo contexto histórico, social e econômico que estavam inseridos - cristianismo conservador norte-americano da década de 1980, entendendo assim que o suicídio de Bobby foi um fenômeno psicossocial atravessado também por esses fatores, que foram por ele internalizados. A clínica históricocultural foi utilizada como possibilidade de trabalhar as demandas elencadas e construir novos caminhos para Mary partindo da mediação dos seus processos de luto, sofrimento e culpa, passando por um processo doloroso de conscientização do seu papel no sofrimento de Bobby, e, por fim, possibilitando a construção de novos caminhos.

Palavras-chave: Orações para Bobby; Teoria histórico-cultural; Clínica históricocultural.

\section{PRAYERS FOR BOBBY: A CASE STUDY FROM THE LOOK OK HISTORICAL- CULTURAL PSYCHOLOGY}

\begin{abstract}
:
This work aimed to interpret the real story narrated in the film Prayers for Bobby, focusing on the protagonista Bobby and his mother Mary Griffith, from Lev Vigotski's historical-cultural theory, showing the possibility of intervention based on the psychotherapy historical-cultural. The relation with the theory made it possible to understand the behaviors of toth characters as directly influenced by the historical, social and economic context that were inserted - conservative american christianity in the 1980's, thus understanding that Bobby's suicide was a psychosocial
\end{abstract}

${ }^{1}$ Graduanda em Psicologia pela Faculdade Católica Dom Orione. Coordenadora do núcleo da Associação Brasileira de Psicologia Social de Araguaína, Integrante da Comissão Especial Psicologia e Povos do Cerrado do Conselho Regional de Psicologia 23. Email: maisamlab@gmail.com

${ }^{2}$ Graduando em Psicologia pela Faculdade Católica Dom Orione. Interesse nos temas: Análise do Comportamento, Políticas Públicas e Psicologia Educacional. E-mail: samuel.mnz12@gmail.com

${ }^{3}$ Doutorando em Psicologia pela Universidade Estadual Paulista "Júlio de Mesquita Filho" (UNESP/ Assis) em que é membro do grupo de pesquisa PsiCUqueer - Coletivos, Psicologias e Culturas Queer. Mestre em Psicologia pela Universidade Estadual de Maringá (UEM). Psicólogo pela Universidade Federal de Mato Grosso do Sul (UFMS/ CPAN). Professor da Faculdade Católica Dom Orione (FACDO). E-mail: gilsonpsico@gmail.com

(c) (1) (3) Perspectivas em Diálogo, Naviraí, v. 8, n. 16, p. 246-258, jan./abr. 2021. 
phenomenon crossed by these factors, which were internalized by him. The historicalcultural clinic was used as a possibility to work with the listed demands and build new paths for Mary drom the mediation of her grieving, suffering and guilt processes, going through a painful process of awareness of her role in Bobby's suffering, enabling the construction of new paths.

Keywords: Prayers for Bobby; Historical-cultural theory; Historical-cultural clinic.

\section{Introdução}

O estudo que se apresenta tem como objetivo interpretar a história real narrada no filme Orações para Bobby a partir da teoria histórico-cultural de Lev Vigotski, mostrando a possibilidade de intervenção a partir da psicoterapia baseada nesta abordagem. Buscando modos mais abrangentes de estudar os processos psicológicos humanos, Vigotski (1896 - 1934) imprimiu em sua obra as características de seu tempo histórico. No berço da revolução russa, revolucionou também a psicologia: escolhendo tratar sobre os problemas reais da existência humana, abordando os fenômenos psicológicos historicamente (OLIVEIRA. RÊGO, 2010).

A produção vigotskiana nasceu e foi orientada para o atendimento de demandas práticas e problemas sociais situados em um contexto pós-Guerra Mundial, Revolução Russa e a Guerra Civil Russa. Vigotski reformula uma psicologia que era paradoxal: de um lado, uma psicologia subjetiva que acreditava que todo fenômeno psíquico era manifestação do espírito e negava o naturalismo, por outro, a psicologia naturalista, própria do positivismo evolucionista, que reduzia a ação dos complexos acontecimentos psicológicos a mecanismos elementares, considerando as atividades conscientes do homem como resultado direto da evolução do mundo animal (BRAGA, 2010).

A autora anteriormente citada afirma ainda que essa produção era uma forma de se opor a ambas. Seus estudos da consciência foram influenciados por Marx e Engels, concluindo que as origens do comportamento consciente deveriam ser buscadas nas condições sociais de vida historicamente formadas. Para essa abordagem, o funcionamento psicológico se deve principalmente pelas relações sociais, que se desenvolvem no interior da cultura e da história, entendendo assim que todo fenômeno psicológico é considerado um processo de mudança, ou seja, são tratados historicamente.

Os processos individuais, dessa forma, passam a ser entendidos como mediados pelas relações sociais. Por isso, a psicologia histórico-cultural é escolhida aqui como óculos para observar os casos de Bobby e Mary Griffith, narrados no filme Orações para Bobby. Para entender o sofrimento do protagonista, de sua mãe e de todos os envolvidos na trama, é necessário interpretá-los como o produto de uma época e cultura específicas que organizaram suas relações entre si e, consequentemente, suas subjetividades.

A identidade norte-americana, por diversos fatores históricos, se constitui a partir do cristianismo, uma nação sob Deus. Sendo influenciada pela Guerra Fria (1947-1991), essa identidade se reafirmou a partir de outros fatores intrinsecamente ligados, como anticomunismo, valores sexuais tradicionais e liberalismo econômico. 
Durante os anos 1980, grupos neoconservadores e fundamentalistas cristãos se uniram para construir uma agenda política conservadora no país (ALVES-JÚNIOR; TROVÃO, 2016).

A homossexualidade, que sempre foi alvo de ataques nos Estados Unidos, se tornou foco principal, pois não se enquadrava no sonho norte-americano pós-guerra, permeado pela moralidade calvinista, que ditava os comportamentos individuais, e o liberalismo, sendo alvo de uma guerra travada pela mídia e a polícia. Além disso, nos anos 1970, durante um período de recessão econômica e escassez de produtos e serviços, seguindo nos anos 1980 com uma necessidade de reorganização da família e do Estado, deu lugar ao avanço de pautas neoliberais na economia e do conservadorismo, que se consolidou com a chegada de Ronald Reagan à presidência, com sua ideia de recuperar a América como redentora do mundo (AZEVEDO, 2001).

É nessa conjuntura política entre o final dos anos de 1970 e início de 1980, que Bobby Griffith se descobre homossexual, no seio de uma família tipicamente cristã e conservadora dos Estados Unidos. Bobby cresceu sendo querido e amado pela família que, sob o comando da mãe, levava a vida na terra em busca da vida em conjunto no céu, no decorrer da história se percebe pecador e diferente dos demais. Temendo não ser mais digno do amor de sua família e do paraíso, os conflitos internos o levam a uma primeira tentativa de suicídio que, mesmo não se concretizando (também por medo de perder o paraíso, pois, para a visão cristã seguida pela família, é pecado tirar a própria vida), se torna o pontapé inicial de sua morte, pois o irmão descobre e conta aos pais. A partir disso, começa o seu calvário, repleto de orações, consultas psicológicas, castigos, versículos bíblicos de arrependimento e abnegação, com sua mãe, Mary, no papel de juíza moral.

A história de Bobby se confunde com a realidade de muitos homossexuais norte-americanos desse período e serve, aqui, como exemplo de que o contexto econômico, histórico e social interfere de maneira concreta na construção de subjetividades - e na sua morte. Assim, esse trabalho se desenvolve pelo olhar vigotskiano, buscando interpretar, a partir de seus pressupostos teóricos, 0 sofrimento de Bobby e sua mãe, apontando possíveis caminhos a partir da psicoterapia, entendendo que, conforme Marangoni (2012), na abordagem históricocultural, o sujeito é visto para além de um diagnóstico que vê seu sofrimento de forma isolada.

\section{Subtítulo: referencial teórico}

Não quero descobrir a natureza da mente fazendo uma colcha de retalhos de inúmeras citações. 0 que eu quero é, uma vez tendo aprendido a totalidade do método de Marx, saber de que modo a ciência tem que ser elaborada para abordar o estudo da mente.

(VYGOTSKY, 1978)

Para construir o Capital da Psicologia, Vigotski (1931/2007) precisou criar uma teoria-método, uma nova forma de conceber o comportamento humano. A característica básica do mesmo, para ele, é que os próprios homens influenciam sua relação com o ambiente, modificando seu comportamento e, assim, controlando-o. Ou seja, o comportamento possui funções voluntárias e o homem não é mais alguém 
que apenas é comandado por reflexos e condicionamentos, mas pode modificar o ambiente e a si mesmo. Este ambiente é, antes de tudo, situado historicamente. Em toda a sua obra, Vigotski aborda um ser humano que se produz e reproduz pela socialização no sistema capitalista, sendo capaz de transformá-lo através de sua autonomia e tomada de consciência.

Esta modificação parte do desenvolvimento da criança, que o autor não divide em etapas, mas afirma ser um espiral de evoluções e revoluções. As funções psicológicas elementares são transformadas em funções psicológicas superiores através do uso de meios artificiais, da transição para a atividade mediada. A atividade passa a ser mediada pelos instrumentos, que levam a mudanças nos objetos e são orientados externamente, e dos signos, que são orientados internamente e servem para o controle do próprio indivíduo. A linguagem, nesse sentido, surge como signo por excelência, por meio dela as crianças têm acesso às produções da história e da cultura e são habilitadas a usarem instrumentos para solucionar tarefas, superar a ação impulsiva e planejar a resolução de um problema antes de executá-lo.

Em A Construção do Pensamento e da linguagem (1934/2001), Vigotski delineia a relação interior entre o pensamento e a palavra no período mais primário do desenvolvimento filogenético e ontogenético, verificando a existência de uma fase pré-intelectual no processo de formação da linguagem e de um estágio prélinguagem no desenvolvimento do pensamento. O pensamento e a palavra, dessa forma, não estão ligados entre si por um vínculo primário. Estes manifestam-se, modificam-se e evoluem-se no processo do próprio desenvolvimento.

No significado da palavra o autor encontra uma unidade que reflete a forma mais simples do pensamento e da linguagem, sendo indecomponível dos dois processos: "A palavra desprovida de significado não é palavra, é um som vazio" (VYGOTSKY, 1934/2001. p.398). Na ótica da psicologia, o significado da palavra não é senão uma generalização ou conceito, generalização e significado são sinônimos. Entendendo que esse ato é o mais específico e autêntico do pensamento, consequentemente, pode se considerar a palavra como um fenômeno de pensamento, estando relacionado a materialização do discurso.

A descoberta introduzida nessa investigação é que os significados das palavras se desenvolvem e mudam, permitindo, pela primeira vez, superar a definição da constância e da uniformidade do significado da palavra. Na velha psicologia, a ligação entre palavra e significado é uma simples associação que se dá em função da coincidência na consciência, com a impressão deixada tanto pela palavra e pelo objeto nomeado pela palavra. Deixando o sentido de que o significado é estabelecido e não pode deixar de desenvolver-se ou sofrer mutação, reduzindo todo o desenvolvimento associativo entre palavras e objetos isolados.

Nesse processo histórico da língua, modifica-se a estrutura e a natureza psicológica desse significado, evoluindo das formas primárias de generalização a formas superiores e complexas, onde a palavra adquire outros significados tanto no conceito concreto, quanto no caráter da representação e da generalização da realidade. Em último, no funcionamento do pensamento falado de uma pessoa, não podemos descobrir nada fora de um movimento linear contínuo, que se realiza em uma superfície associativa entre palavra e seu significado (VYGOTSKY, 1934/2001).

Para entender a dinâmica das relações que o autor propõe é necessário que se faça um corte transversal na estrutura genética de mudança que se desenvolve na investigação preliminar, ressaltando o papel funcional do significado da palavra no 
ato de pensar. Este passar do plano genético para o plano funcional significa delinear não só o processo de desenvolvimento dos significados, mas o processo do funcionamento no curso vivo do pensamento verbal, sua estrutura e relações específicas e a formação de novos conceitos.

O discurso falado, como vimos anteriormente, desde o início está ligado à consciência e à intencionalidade. Por isso, o diálogo quase sempre conclui em si a possibilidade da não-conclusão do enunciado, da enunciação incompleta, da inutilidade de mobilizar todas as palavras que devem ser mobilizadas para revelar o mesmo complexo concebível nas condições do discurso monológico (VYGOTSKY, 1934/2001. p.456).

A palavra é soma de todos os fatos psicológicos que ela desperta na consciência. Assim, o sentido é constantemente uma formação dinâmica e complexa, que existem várias zonas de estabilidade. O significado é apenas uma zona que é mais estável. Como se sabe, as palavras mudam de sentido dependendo do contexto, com isso, o significado é um ponto imóvel que permanece estável em todas as mudanças de sentido da palavra em diversos contextos.

Com isso, para entender o discurso do outro, não basta apenas entender umas palavras, torna-se essencial compreender seu pensamento. Mesmo sendo incompleto o alcance do pensamento do interlocutor sem a compreensão do motivo que levou a emiti-lo. Para fazer uma análise psicológica de discurso só se chega ao fim quando se descobre o plano interior e mais encoberto do pensamento verbal, a sua motivação.

A consciência se reflete na palavra como o sol em uma gota de água. A palavra está para a consciência como o pequeno mundo está para o grande mundo, como a célula viva está para o organismo, como o átomo para o cosmo. Ela é o pequeno mundo da consciência. A palavra consciente é o microcosmo da consciência humana (VYGOTSKY, 1934/2001. p.486).

Por isso o pensamento e a linguagem são a chave para o entendimento da natureza da consciência humana. A palavra desempenha o papel central na consciência e não funções isoladas. Entendendo a importância da palavra, se entende também a importância da clínica, como um processo de tomada de consciência através da fala, Vigotski, todavia, só começou a priorizar os estudos da clínica muito próximo de sua morte. Sendo assim, o que se tem como produção de psicoterapia histórico-cultural foi elaborado pelos seus seguidores, que aplicam seus conceitos principais no trabalho clínico (LIMA; CARVALHO, 2013).

Gozález Rey (2007), um dos maiores expoentes do enfoque histórico-cultural na psicologia clínica, afirma que o referencial teórico utilizado neste é essencialmente diferente dos dominantes no cenário das teorias terapêuticas, pois parte de uma diferente concepção de homem. Assim, não oferece um sistema de regras universais para a prática terapêutica, mas princípios gerais para fundamentá-la: 1) a psicoterapia enquanto processo de diálogo vai se configurar como um processo único e relacional entre o sujeito e o psicólogo, atravessando processos de sentido e significação associados aos espaços da subjetividade social do sujeito; 2) a qualidade do diálogo nesse processo único irá determinar as novas produções do sujeito, reposicionando-o na relação original com seus processos; 3) o terapeuta vai agir a partir da relação, do diálogo, não com esquemas concebidos rigidamente. 


\section{Resumo do filme}

Iniciando cronologicamente em 1979, no aniversário da avó do protagonista, o filme conta a história de Bobby Griffith, um dos quatro filhos de um casal cristão americano. A família, nas primeiras cenas, aparenta ser feliz, comunicativa e unida. A mãe, Mary Griffith, aparece como a figura principal no cerne familiar, unindo todos em torno de uma causa comum: a ida, em conjunto, de toda a família para o reino dos céus. Aqui, três acontecimentos devem ser destacados: o desconforto de Bobby ao ouvir a avó dizendo que, para ela, os "viados" deveriam ser todos enfileirados e mortos; a irmã acusando Bobby de ser perfeito e o preferido da família (o que se percebe nas cenas em que acerta as perguntas bíblicas); além de ser nesse contexto que ele toma para si o diário que a irmã comprou para a avó.

Na cena seguinte, Bobby aparece aos beijos com uma menina, que diz estar pronta para avançar na relação, tornando-a sexual, o que leva ao término dos dois. Após isso, o protagonista se dirige para a boate gay que irá aparecer outras vezes no decorrer no filme, mas não entra. A partir deste episódio, torna-se claro o motivo do desconforto demonstrado por Bobby na primeira cena. Tenta conversar com o irmão sobre o assunto, mas não consegue, dizendo apenas que tem algo de errado com ele e tem medo de não ir para o céu com o resto da família. A angústia e o medo crescem e se tornam tema dos escritos em seu diário, onde relata ver em um penhasco e ter medo de voar.

Pega um frasco de remédios para se matar. Quando o irmão chega em casa, estranha o silêncio e o encontra deitado com os remédios e se desespera, mas logo percebe que o mesmo não conseguiu, por também julgar que a morte voluntária seria pecado. Após isso, conta para o irmão que não consegue ser como ele, apesar de tentar, e este promete que não vai contar para os pais - mas conta, e os medos de Bobby se tornam reais.

A mãe, assumindo a responsabilidade da salvação de sua família, começa uma cruzada contra o que acredita ser o pecado e a doença do filho. Sua vida se converte na conversão de Bobby. Começa a estudar a bíblia e colar versículos por toda a casa sobre pecado, perseverança e salvação em Deus. Além disso, leva o filho a uma psiquiatra que trata a homossexualidade ora como doença, ora como algo que só se é por querer e diz que precisa passar mais tempo com o pai e o irmão, pois talvez seja falta de uma figura masculina, um pai ausente e uma mãe exigente demais.

O pai, ao contrário da mãe, é contra forçá-lo ao que não tem interesse, mas acaba cedendo aos desígnios da esposa. As estratégias utilizadas são muitas, vigília e oração em volta da cama de Bobby, obrigatoriedade de participar de uma espécie de grupo de jovens na igreja e encontros forçados com garotas. Com isso, é notório um movimento de repulsa da mãe para com o filho, aquele que era o preferido da família agora é motivo de vergonha. A cada situação de briga e constrangimento, se percebe um Bobby cada vez mais distante, com raiva. Em uma das brigas com a mãe, em que ela demonstra estar constrangida de como ele se veste e se porta, a mãe retira-o da frente das amigas, ele vai à boate e beija um rapaz pela primeira vez, indo embora em seguida.

A prima Janette, com quem ele possui um melhor relacionamento, vem visitar a família e acaba discutindo na mesa de almoço por defender que as pessoas deveriam poder amar quem quiserem. A situação se complica e Bobby desiste da escola e da faculdade, anunciando que irá passar as férias em Porland, com a prima. 
$\mathrm{Na}$ ida, escreve no diário que seu objetivo com essa viagem era alcançar um sentimento de orgulho e valor como ser humano, e assim ele faz. Janette apresenta seu amigo David, que o apoia e dá forças, contando como foi seu processo de aceitação familiar, e eles acabam se apaixonando.

Ao final das férias, quando chega em casa, conta para a família que conheceu alguém, mas a mãe se recusa a ouvir. Bobby então diz que ela não admite que não suporta o que ele é, dando um ultimato: ou me aceita como eu sou ou me esqueça, ao que prontamente ela responde "eu não vou ter um filho gay". Então ele vai embora de vez para Portland, mas a mãe não se despede dele, apesar de ficar chorando e observando ele da janela. Chegado o dia do seu aniversário, uma data importante e muito comemorada pela família, recebe da mãe um cartão escrito "AIDS" - a ira de Deus", o que o faz perceber que não era mais da família.

Após isso, David leva-o para um jantar na casa dos seus pais, onde é bem recebido, acolhido e amado, isso o deixa mais confuso ainda. Sua situação piora e um dia no trabalho, quando não suporta mais, liga para o namorado querendo conversar, mas esse não atende. Quando sai para procurá-lo, vê que estava com outro cara. Dirige o carro e estaciona na ponte. Enquanto vai saindo do carro e subindo, lembra e vê tudo pelo que passou nos últimos anos, terminando na fala da mãe "eu não vou ter um filho gay" - e se joga.

A primeira a saber é Janette, que avisa para o resto da família. Todos ficam desolados. No velório, o pastor diz que Bobby estava perdido, caiu em tentação e acabou sucumbindo ao pecado. Na casa, onde a família recebe os cumprimentos, a mãe de Bobby se mostra cada vez mais fechada, descontando a dor da perda em preocupações banais, como a comida dos convidados. David os cumprimenta e diz que sente muito, mas logo que ele sai ela lava as mãos e joga o prato em que ele comeu fora. Nessa mesma noite, sonha com Bobby e começa a ler seus diários - a grande virada.

Em uma reunião com os pastores, pergunta o que a igreja faz por esses jovens como o seu filho. Inicia um calvário de questionamentos: duvida de Deus, da sua fé, se culpa, não consegue fazer sexo com o marido - toda a sua vida se converte em entender o que acontecer com o filho. Encontra, em suas leituras, um papel da Igreja Metropolitana, indo para lá em busca de respostas. Estranha tudo, pois a igreja é majoritariamente frequentada por homens de aparência considerada socialmente como mais afeminada. O Reverendo Whitsell a recebe bem, diz que lembra do Bobby e sente muito pela sua perda, mas ela começa a acusá-lo usando frases bíblicas, ao que ele responde com contexto histórico e demonstrando o amor de Deus. Após isso, diz que as portas da igreja estão abertas para ela, mas não para que ela o acuse, entregando um cartão da P-FLAG (sigla em inglês que significa "Associação dos Pais e Amigos dos Gays e Lésbicas).

Os questionamentos não saem da cabeça de Mary e começam a afetar sua vida pessoal e casamento, então resolve chamar uma mãe da Associação para conversar, logo depois indo em uma reunião do grupo. Lá, pôde ver pais em situação semelhante à sua, mas que vivem bem com seus filhos, o que a leva a colocar em palavras sua angústia "não tinha nada de errado com ele... eu fiz isso", ao que o reverendo responde que Deus já deu seu perdão, falta ela perdoar a si mesma. A partir disso,

1 A AIDS, nessa época, era conhecida como a doença dos gays e interpretada como um castigo de Deus para os seus pecados (SAEZ; CARRASCOSA, 2016) 
da angústia e dos questionamentos, torna-se ativista dos direitos dos homossexuais, fazendo um discurso emocionante em rede nacional e participando, em 1984, da Parada do Orgulho Gay. Lá, sai um pouco do percurso para dar um abraço em um menino extremamente parecido com Bobby, onde fica claro que o seu perdão se consumou.

\section{Procedimentos Metodológicos}

Entre as contribuições de Vigotski fundamentais para a psicologia elencadas por Daniels (2011), três foram consideradas cruciais para a construção e o desenvolvimento deste trabalho: 1) a síntese dialética ou transformação de elementos contraditórios em todos coerentes; 2) a perspectiva desenvolvimental, que analisa os processos em mudança e movimento e 3) o antirreducionismo, a necessidade de estudar o processo integralmente.

A interpretação se utiliza da história do filme, mas dá a ela novos contornos. Dividindo a história em duas partes - que não se separam, mas são unidades de um todo: inicialmente, será feita uma pequena interpretação dos sentidos e significados do suicídio de Bobby dentro da história. Após isso, a transformação de sua mãe, mediada pelo acesso ao seu diário, e as demandas clínicas que envolveram esse processo e como a clínica-sócio histórica pode ajudar a construir novos caminhos a partir delas.

\section{Resultados e discussões}

A teoria histórico-cultural aplicada à clínica aborda que, para entender o comportamento humano, necessita-se considerar o componente fisiológico (materialismo), cultural/simbólico (conjunto de signos) e a história, compreendendo assim que o desenvolvimento da personalidade se dá através das relações com outras pessoas, processos sociais de significação (GUNLANDA; GOMES; BAADE, 2017). O contexto em que Bobby viveu e se construiu enquanto sujeito foi definido principalmente pela família e pela igreja. Nesse ambiente, Bobby entra em conflito, pois os sentimentos e os vínculos criados com a família começam a ter novos significados e tudo que aprendera em sua vida familiar e religiosa adquire novos sentidos.

Daniel Júnior (2012) declara que a realidade e a subjetividade são percebidas de maneira dialética, pois os elementos formadores são causa e efeito de um e do outro em simultâneo, encontrando-se em constante relação e transformação. Nesse sentido, o desenvolvimento está intrinsecamente ligado a condição que o indivíduo está envolvido com a cultura, com significados que orientam a funcionalidade dos objetos, o modo de ser, agir e de interagir com os outros (GOMES et al., 2016).

Bobby vive um processo de estranhamento, não se reconhecendo em sua antiga realidade e sendo infeliz na nova. Este, no materialismo-histórico-dialético, é ocasionado pela alienação, que diz respeito a separação do produtor do seu produto no capitalismo, resultando na separação do sujeito de si mesmo - ou seja, esse estranhamento se dá pela perda ou desconhecimento das motivações que conduzem as suas atividades. Dessa forma, age no mundo sem se reconhecer como sujeito único, sem reconhecer a que lugar pertence, sem perceber que seus pares estão submetidos as mesmas condições. Assim, são criadas situações para que, por estar 
alheio as consequências de suas ações, possa realizar atos que prejudiquem sua vida, mesmo que o intuito de morrer não seja o real motivo, mas apenas de acabar com o seu sofrimento (NETTO; SOUZA, 2015).

O suicídio, para Netto (2007), é um fenômeno socialmente construído e possui significados que lhe são atribuídos, mas, em simultâneo, é uma ação singular e de caráter particular - se relacionando com toda a história individual do sujeito e o sentido que atribuiu aos fenômenos vivenciados. Bobby se suicidou, mas antes já morrera ao não ter seus direitos garantidos, ao ter perdido a convivência e o carinho de seus familiares, ao perder toda a base e o afeto que lhe sustentava. A internalização, conceito que explica a reconstrução interna de uma operação externa, a transformação de um fenômeno social em psicológico (BRAGA, 2010), ajuda a compreender o que o preconceito fez em sua subjetividade.

A teoria de Vigotski é considerada revolucionária porque, além de entender que os processos internos advêm das relações externas, possibilita o entendimento e a possibilidade de transformar ambos. Após o suicídio de Bobby, sua mãe passa a protagonizar o filme. Em determinado momento, depois de seu enterro, encontra o diário, onde entra em contato com o sofrimento do filho e inicia o seu processo de mudança - extremamente doloroso. A zona de desenvolvimento proximal, cunhada por Vigotski é, segundo Newman e Holzman (2002), uma unidade revolucionária, pois reconhece o estado de desenvolvimento como definido também pelo que está em processo. Esse conceito, de forma didática, representa o espaço entre o que a pessoa tem condições de fazer sozinha e o que poderá fazer com a mediação de alguém.

A dor que Mary enfrenta para adquirir consciência do papel da igreja e de seu discurso tiveram sobre o sofrimento de Bobby foi, durante muito tempo, um entrave para perdoar a si mesma, se reorganizar e se mobilizar para ajudar outras pessoas. Dessa maneira, uma intervenção clínica seria uma forma de mediar esse processo, pois o desenvolvimento psicológico, nessa abordagem, considera o consolidado e focaliza o emergente, o que é potencial (GOÉS, 1991).

A psicoterapia baseada nos pressupostos teóricos elencados no decorrer do trabalho visa romper os processos de fragilização do sujeito, pois acredita que a saúde psicológica está na possibilidade de enfrentar seu contexto cotidianamente, construindo soluções para os problemas que se apresentam (BOCK, 2007). Mary, dessa forma, poderia trabalhar na psicoterapia os sentidos e significados atribuídos por ela a morte de Bobby, a religiosidade, a homossexualidade e demais aspectos envolvidos em seu sofrimento. Também seria interessante que a psicoterapia a auxiliasse a tomar consciência dos significados sociais e dos determinantes históricos que atuaram para a construção do sofrimento de Bobby.

Nesse sentido, o adoecimento aparece, muitas vezes, como uma resistência passiva à organização do processo de trabalho e da vida, denunciando as contradições do capitalismo que se reinventa para continuar a exploração (ALMEIDA, 2018). Entender o movimento social geral contribui para explicar o desenvolvimento da vida nos grupos, enquanto o avanço na vida dos grupos contribui para explicar como os transtornos de saúde dos indivíduos são produzidos - o processo de saúdedoença se configura como uma expressão particular do processo geral da vida social (BREILH, 1979, 1991)

Entendendo esse processo que passa do universal para o singular, na psicoterapia, também como uma interação social, a psicóloga de abordagem 
histórico-cultural assumiria um papel de mediadora, auxiliando Mary a nomear seus sentimentos, identificar seus sentidos e construir novos, a partir disso. Uma técnica essencial para tal ação seria a contextualização, explicada como o processo colocar em contexto os mitos adquiridos pelo sujeito ao longo de sua vida. Dessa forma, Mary poderia chegar mais facilmente à compreensão de que a sua convicção sobre o pecado da homossexualidade era construída pelo meio em que estava inserida (LIMA; CARVALHO, 2013).

Essa é uma das particularidades da atuação clínica na Psicologia HistóricoCultural, compreender o sujeito inserido no seu contexto para que o psicoterapeuta possa facilitar seu processo de busca por respostas (FERREIRA; ROUDÃO, 2018). Compreender Mary enquanto inserida em uma realidade específica e, em paralelo, possibilitar que ela também se entenda dessa forma, deve ser um dos objetivos principais dessa intervenção.

O espaço de fala e, principalmente, de escuta da psicoterapia, auxiliaria Mary a nomear o que estava sentindo durante seu processo de luto, se conhecendo e reconhecendo em suas palavras. Isso acontece porque o psicoterapeuta de abordagem histórico-cultural interfere na zona de desenvolvimento potencial do paciente, facilitando processos psíquicos sobre os quais este não conseguiria sozinho. Esta tem como objetivo possibilitar a reelaboração das ações através de novas interpretações, confrontos e ressignificações (PÉREZ, 1999). Com a intervenção psicológica efetiva e teoricamente alicerçada, esse falar traria alívio e possibilidade de construção de novos caminhos.

\section{Considerações finais}

Ao longo do trabalho, se pôde perceber que, conforme nos aponta a teoria histórico-cultural, o desenvolvimento humano se constitui socialmente, bem como todos os sentidos atribuídos ao mesmo. Ao interpretar o caso de Bobby sobre essa ótica, foi possível entender que sua vida e a vida de sua família foram afetadas de forma subjetiva e concreta pelo tempo histórico, sociedade e modo econômico aos quais estavam inseridos.

Além disso, ficou claro que, além de ser transformado pelo mundo, o indivíduo também pode transformá-lo e que todo processo precisa ser visto em movimento constante. Pensar o ser humano dentro dessa abordagem quer dizer vê-lo a partir de sua materialidade, mas repleto de possibilidades a partir do processo de conscientização sobre a mesma.

A psicoterapia histórico-cultural aplicada a esse contexto, especificamente com Mary, mãe de Bobby, poderia auxiliar no processo de reconhecer os sentimentos e sofrimentos individuais e coletivos causados pelo suicídio, a culpa e o estranhamento que descobrir uma nova forma de viver e interpretar a bíblia e a religiosidade causavam as mesmas, possibilitando a construção de novos caminhos a partir disso. A fala dentro da psicoterapia, nesse sentido, seria um meio para a mesma se reorganizar internamente.

Entretanto, é necessário apontar as limitações do estudo feito aqui. A clínica a partir da perspectiva histórico-cultural, apesar de um campo prático possível, ainda possui pouca produção científica sobre ela. É necessário enriquecer este campo de debates e novas possibilidades teórico-práticas, pois, por fixar seus pés na vida concreta e entender o ser humano como atravessado pelas condições materiais de 
existência, pode trazer uma nova forma de ver e lidar com os problemas individuais decorrentes do modo de produzir e reproduzir a vida sob o capitalismo.

\section{REFERÊNCIAS}

ALMEIDA, Melissa Rrodrigues. A Formação social dos transtornos do humor (Tese de Doutorado). Faculdade de Medicina de Botucatu, Universidade Estadual Paulista "Júlio de Mesquita Filho", Botucatu, SP, Brasil, 2018.

ALVES-JÚNIOR, Alexandre Guilherme da Cruz.; TROVÃO, Flávio Vilas Boas. Conservadores ontem e hoje: um olhar sobre os Estados Unidos dos anos 1980. In: POLLI, José Renato; VARES, Sidnei Ferreira de. Democracia em tempos de conservadorismo. Jundiaí, SP: Editora in House, 2016.

AZEVEDO, Cecilia. A santificação pelas obras: experiências do

protestantismo nos EUA. Tempo, Rio de Janeiro, n011, pp. 111-129, 2001. Disponível em: http://www.historia.uff.br/tempo/artigos_dossie/artg11-8.pdf. Acesso em: 21 abr. 2020.

BOCK, Ana Mercês Bock. A prática profissional em psicologia sócio-histórica. In: BOCK, Ana Mercês Bock; Gonçalves, Maria da Graça.; FURTADO, Odair. (Orgs.).

Psicologia sócio-histórica: uma perspectiva crítica em Psicologia. São Paulo: Cortez, 2007. p. 15-35.

BRAGA, Elizabeth dos Santos. Lev Vigotski - Principais Teses: A constituição social do desenvolvimento. Educação, São Paulo, v. 2, p. 20-29, 2010.

BREILH, Jaime. Epidemiologia: economia, política e saúde. [1979] São Paulo: Editora Universidade Estadual Paulista: Fundação para o Desenvolvimento da UNESP: Hucitec, 1991.

DANIEL JUNIOR, Geraldo Magela. A Psicologia sócio-histórica e o materialismo histórico-dialético. In: FRANCISCHINI, Rosângela; MICHONI, Tatiana; FERREIRA, Emanuelle de Oliveira. (Org.). Crianças e adolescentes: percursos teóricometodológicos de investigação em múltiplos contextos de desenvolvimento. Natal: Editora UFRN, p.15-49, 2012.

DANIELS, Harry. Vygotsky e a Pesquisa. São Paulo: Edições Loyola, 2011.

FERREIRA, Talita Regina Santos; ROLDÃO, Flávia Diniz. A prática clínica na Psicologia Histórico-Cultural. Anais do EVINCI, UniBrasil, Curitiba, v. 4. n. 1, p. 384-397, out. 2018.

GÓES, Maria Cecilia. A natureza social do desenvolvimento psicológico. Cadernos CEDES, São Paulo, n. 24, p. 17-24, 1991. 
GOMES, Isadora Dias. et al. O social e o cultural na perspectiva Histórico-cultural: tendências conceituais contemporâneas. Psicologia em revista, v. 22, n. 3, p. 814-831, 2016.

GUNLANDA, Orlando Aafonso Camutue; GOMES, Allan Henrique; BAADE, Joel Haroldo. Vigotski e a clínica psicológica: considerações a partir de seus escritos. Revista Interdisciplinar de Estudos em Saúde, v. 6, n. 2, p. 217-235, 2017.

LIMA, Paula Márcia de; CARVALHO, Carolina Freire de. A Psicoterapia SocioHistórica. Psicol. Cienc. Prof., Brasília, v. 33, n. spe, p. 154-163, 2013.

MARANGONI, Sinome. Ludoterapia como um vygotskyano faz. 2012. Disponível em: http://www.ipaf. com.br Acesso em: 16 nov. 2020.

NETTO, Nilson Berenchtein; SOUZA, T. M. S. Adolescência, educação e suicídio: uma análise a partir da psicologia histórico-cultural. Nuances: estudos sobre educação, v. 26, n. 1, p.163-195, 2015.

NETTO, Nilson Berenchtein. Suicídio: uma análise psicossocial a partir do materialismo histórico dialético. (Dissertação) São Paulo: PUC-SP, 2007.

NEWMAN, Fred; HOLZMAN, Lois. Lev Vygotsky: Cientista Revolucionário. Belo Horizonte: Editora Loyola, 2002.

OLIVEIRA, Marta Kohl de; REGO, Teresa Cristina. Revolucionário Inquieto. Educação: Lev Vigotski. São Paulo, n. 2. p. 6-17, 2010.

PÉREZ, Dionisio Zaldivar. Psicoterapia y orientacion Historico Cultural. Revista Cubana de Psicologia, 1999. v. 16. n. 3. Disponível em:

http://investigacionpsigestaltintegral.blogspot.com/2015/10/psicoterapia-yorientacion-historico.html. Acesso em: 16 nov. 2020.

REY, Fernando González. Psicoterapia, subjetividade e pós-modernidade: uma aproximação histórico-cutural. São Paulo: Thompon Learning, 2007.

SAEZ, Javier; CARRASCOSA, Sejo. Pelo cu: políticas anais. Belo Horizonte: Editora Letramento, 2016.

VYGOTSKY, Lev Semionovitch. Mind in society: Development of Higher Psychological Processes. Cambridge: Harvard University Press, 1978.

VYGOTSKY, Lev Semionovitch. A Construção do Pensamento e da Linguagem. São Paulo: Martins Fontes, 2001. (Originalmente publicado em 1934).

VYGOSTSKY, Lev Semionovitch. A formação social da mente: o desenvolvimento dos processos psicológicos superiores. 7. ed. São Paulo: Martins Fontes, 2007.

(Originalmente publicado em 1931). 
Recebido em: 16 de setembro de 2020. Aceito em: 19 de novembro de 2020. Publicado em: 05 de janeiro de 2021. 